\title{
Gupta faces suspension
}

\section{New Delhi}

PANJAB University geologist Dr Vishwa jit Gupta has been suspended from his posts at the university at Chandighar in the wake of two reports supporting allegations that his Himalayan fossil collections, the source of the numerous publications spanning two decades, were faked.

Apart from being a professor at the university, Gupta was until his suspension director of the Institute of Palaeontology, supported by the University Grants Committee, and a deputy to the vicechancellor. $\mathrm{He}$ is now being served with a charge-sheet, bringing to an end a twoyear controversy triggered by allegations by $\mathrm{Dr}$ John Talent (see Nature 338, 613-615; 1989 and see also 343, 305-308; 1990 and references therein).

Orders suspending the professor were issued last week by the vice-chancellor of the university, Dr R. P. Bambah, acting on reports of investigations by the Geological Survey of India (GSI) and the Society for Scientific Values (SSV), an independent body of scientists concerned with ethics and morality in scientific research. The two reports concurred in their conclusion that Gupta's Himalayan fossils were not genuine. Gupta was not available for comment.

SSV's report was based on an analysis of samples its team brought back from an expedition to the Himalayas in August 1990. The report was not made public, but was sent only to Bambah with a recommendation for appropriate action against Gupta.

The GSI council, on the other hand, decided to give Gupta a last opportunity to come clean, and sent its report to him with a request to "make his collections available and also provide full details of fossil localities and stratigraphic horizons for independent check". When Gupta failed to respond, GSI published the report in its official journal with a leading article that says: "It is obvious from the volume of evidence that has now been collected that the fossil finds of Dr Gupta are not reliable, that there are internal inconsistencies, that the data is incomplete bordering on disinformation."

The GSI, which scrutinized all of Gupta's papers published between 1969 and 1988, said his work was "fictitious and based on spurious fossils", lending support to accusations of questionable practices such as recycling of fossils, plagiarism and scientific misconduct.

Checks by GSI officials and some of Gupta's own colleagues revealed neither the fossils nor the rock formations said to have been present in the areas from which fossils were supposed to have been collected. According to the report, Gupta's replies to the charges were evas- ive. "He failed to produce originals of fossils with their registration numbers, dates of collection, field notebooks, laboratory registers and other evidences to confirm the genuineness of his collections."

Both SSV and GSI reports were available to Bambah last December, but HIGH-PERFORMANCE COMPUTING
Gupta's well-wishers wanted the matter referred to a retired judge of the high court. As recently as the beginning of this month, the university was making arrangements for this further inquiry.

But Bambah has now ordered Gupta's suspension because, as one faculty member remarked, "the episode has brought disgrace to the Indian science community".

K. S. Jayaraman

\section{London}

IN order to compete with the United States and Japan in high-performance computing, Europe should increase its annual investment in the area by 1,000 million ECU (European Currency Units, about $f 700$ million) by 1995 . That is the conclusion of an expert working group of European supercomputer users chaired by Carlo Rubbia, director-general of the CERN European particle physics centre.

As noted in the committee's report, almost all high-performance computers are now manufactured in either the United States or Japan, even though European users account for some 30 per cent of the world market. And the next generation of high-speed computer is under development. Machines capable of one million million operations per second, almost a thousand times faster than today's best supercomputers, may be possible by the turn of the century.

The working group, which was set up by the European Commission in 1990, sees this next generation as a window of opportunity for Europe. The report of the working group, however, left many questions unanswered. It did not detail exactly who is likely to pay for the programme or even how the burden should be shared between the public and private sectors. And just how the group arrived at 1,000 million ECU per year as an appropriate increase - which the report characterizes as an "order of magnitude" figure - is equally unclear.

Group members were last week unable to say how much Europe currently spends on its high-performance computing industry. Instead, Commission officials say they were influenced by the level of new investment already planned in the United States. President George Bush's science budget request to Congress for 1992 proposes a 30 per cent increase in high-performance computing research funding, up to $\$ 638$ million, as part of an initiative that will also include private-sector spending.

Some critics question whether a European programme in high-speed computing would have tangible economic returns and suggest that the request for massive supercomputing investment is motivated more by questions of prestige.
Martin Campbell-Kelly, a historian of the computer industry at the University of Warwick, says that there is no convincing evidence that investment in supercomputer manufacturing and research produces strong "trickle-down benefits" for the computer industry as a whole. He believes the ailing European industry would benefit more from investment in the development of smaller machines, where the potential market is larger.

Apart from the massive US government investment in high-performance computing companies from the $1950 \mathrm{~s}$, to provide computing power for the US atomic weapons programme, US companies win over their European counterparts in having a large single domestic market to exploit. Bill Trebinski, marketing manager for the British company Active Memory Technology (AMT), the leading European manufacturer of massively parallel supercomputers, says his company finds it easier to sell in the United States than across Europe, where each country must be treated as a separate small market. But there is also a "psychological problem", Trebinski says, in that both US and European supercomputer users assume US machines are more advanced. AMT, which earns more than 60 per cent of its revenue in the United States, is often thought of as a US company, Trebinski says.

The forthcoming 'single European market', due in 1992, may break down many of the trading barriers that restrict the European high-performance computing industry. But Tor Bloch, a member of the Rubbia working group, says Europe must also work to create a "common culture" for its supercomputer users, if the single market is to become a reality in high-performance computing.

Europe needs "the computing equivalent of CERN", says Bloch, whose own organization, the Advanced Computing Research Institute of Lyon in France, is now assembling an international team to design new high-speed computers.

To this end, the Rubbia group's report says that 200 million ECU of the 1,000 million ECU a year is needed to establish high-speed electronic networking between supercomputers and service centres throughout Europe.

Peter Aldous 